\title{
MELIHAT SISI FUNGSIONAL RUMAH IBADAH \\ Studi terhadap Masjid dan Gereja Katolik di Kecamatan Sukajadi Kota Pekanbaru
}

\section{Azwan}

Jurusan Studi Agama-Agama Fakultas ushuluddin UIN Sultan Syarif Kasim Riau Email: azwanbungsu99@gmail.com

\section{Abd Ghofur}

Jurusan Studi Agama-Agama Fakultas ushuluddin UIN Sultan Syarif Kasim Riau Email: abd.ghafur@uin-suska.ac.id

\author{
Khairiah, M.Ag
}

Jurusan Studi Agama-Agama Fakultas ushuluddin UIN Sultan Syarif Kasim Riau Email: khairiyah@uin-suska.ac.id

\begin{abstract}
Abstrak
Penelitian ini, merupakan field research (penelitian lapangan) dengan metode pendekatan studi komparatif. Pendekatan yang digunakan adalah kualitatif yang besifat deskriptif-analitis. Hasil penelitian menunjukkean babwa secara fungional, keberadaan Masjid Jami' dan Gereja Katolik Santa Maria memilike persamaan, terutama pada bidang pendidikan. Jika di Masjid ada TK dan MDTA, maka fungsi pendidikan di Gereja Katolik Santa Maria ada TK Santa Maria, SD Santa Maria dan SMA Santa Maria. Pada aspek ibadab, keduanya juga memili fungsi yang sama. Begitu juga pada aspek social-kemasyarakatan, keduanya juga memiliki fungsi yang sama. Jika di Masjid memberi bantuan terbadap anak yatim dan memberikan bantuan terbadap masyarkat yang kurang mampu, maka di Gereja Katolik Santa Maria juga memberikan bantuan sosial terbadap Masyarakat yang kurang mampu.
\end{abstract}

Kata kunci; Keragaman, Gotong Royong, Keindonesiaan

\section{Pendahuluan}

Pada setiap agama terdapat ajaranajaran yang harus dipatuhi oleh penganutnya. Salah satu aspek ajaran agama yang dikerjakan adalah ibadah. Adapun contoh ibadah yang harus dilakukan contohnya sholat didalam agama Islam yang diamalkan dalam 5 waktu sehari semalam. Lalu ada juga contoh yang lainnya ibadah rohani dalam agama Katolik.
Dalam pelaksanaan ibadah tersebut para pemeluk agama melakukannya didalam rumah ibadah. Rumah ibadah di dalam agama Islam adalah Masjid. Di dalam Masjid ini umat Islam biasanya melakukan sholat, tablig akbar dan pengajian wirid yang dilakukan oleh umat Islam.

Secara bahasa kata masjid adalah tempat yang dipakai untuk bersujud. Kemudian maknanya meluas menjadi 
bangunan khusus yang dijadikan orangorang untuk tempat berkumpul dalam menunaikan shalat berjama'ah. AzZarkasyi berkata, "Manakala sujud adalab perbuatan yang paling mulia dalam shalat, disebabkan kedekatan hamba Allah kepadanya didalam sujud,maka tempat melaksanakan shalat diambil dari kata sujud (yakni masjid = tempat sujud.)

Pada penelitian ini, penulis ingin membahas bagaimana sejarah dan fungsi masjid dan gereja katolik. Adapun focus penelitian ini adalah tentang sejarah dan fungsi Masjid dalam Islam dan Gereja Katolik. Hanya mengetahui tentang persamaan dan perbedaan Masjid dan Gereja Katolik

Sumber Data Penelitian diperoleh melalui data primer dan sekunder. Data primer adalah adalah pengambilan data dengan instrumen pengamatan, melalui buku, dan jurnal dan penggunaan dokumen. Sumber data primer merupakan data yang diperoleh langsung dengan melalui buku, dan jurnal. Sementara pada Data Sekunder, data yang digunakan untuk mendukung data primer yaitu melalui studi kepustakaan, buku, majalah, koran, arsip tertulis yang berhubungan dengan obyek yang akan diteliti pada penelitian ini.

\section{Gereja Katolik Santa Maria}

1. Sejarah Gereja Katolik Santa Maria

Pada awal tahun 1925, hanya ada beberapa orang katolik di Pekanbaru, tepatnya berdomisili di Rumbai.
Seiring berjalannya waktu, penduduk kota bertuah semakin meningkat, peningkatan ini terutama sejak diadakannya eksplorasi penambangan minyak mentah di daerah Riau melalui kerjasama bilateral Indonesia Amerika Serikat. Para pendatang yang masuk ke kota Pekanbaru ini berasal berbagai daerah dengan latar agama dan budaya, termasuk yang beragama Katolik (File Gereja Katolik Santa Maria, 2020).

Beberapa warga katolik kemudian membentuk kelompok kecil dan berupaya untuk mendapatkan pelayanan iman. Paroki terdekat dengan wilayah Pekanbaru adalah paroki Payakumbuh. Oleh sebab itu, datangla pastor paroki Payakumbuh secara teratur. Dengan demikian saat itu wilayah Pekanbaru merupakan stasi dari paroki Payakumbuh.

Di sebelah gedung Gereja ada sebidang tanah yang cukup luas. Pemilik adalah seorang yang bukan beragama Katolik yaitu Bapak Yap Tek (ayah dari Bapak Abubakar). Setelah ada dari persetujuan dari kedua belah pihak maka tanah itu pun dibeli oleh pihak Gereja. Kemudian izin untuk membangun Gereja pun di urus.

Setelah segala sesuatu selesai maka pada bulan maret 1963 bapak Uskup Raimondo Bergamin, SX dan Bapak Gubernur Riau yang waktu itu 
dijabat oleh Bapak Khaharudin Nasution meletakkan batu pertama, sebagai tanda dimulainya pembangunan gedung Gereja yang baru tersebut.

Pada tahun 1963 itu yang menjabat sebagai kepala Paroki adalah Pastor Aniceto Morini, SX. Mulai terlaksananya pembangunan ini tentunya tidak terlepas dari hasil kerja keras dari Pastor A. Morini, SX selaku pastor kepala Paroki bersama pastorpastor yang bertugas di Pekanbaru lainnya. Para pastor tersebut adalah Pastor Silvano Laurenzi, SX, Pastor Albino Orsi, SX, Pastor Angelo Calvi, SX, dan Pastor Abdon Fantelli, SX. (File adm Gereja Katolik Santa Maria, 2019)

\section{Fungsi Gereja Katolik Santa Maria}

Pertama, Fungsi Gereja di Bidang Pendidikan. Pendidikan merupakan sesuatu yang pening untuk memajukan bangsa pemerintah Indonesia berupaya untuk memajukan pendidikan di Indonesia guna mencapai masyarakat yang sejahtera. Pendidikan merupakan suatu sarana yang dapat menghantarkan manusiauntk dapat mencapai kemajuan, oleh karena itu bidang pendidikan adalah salah satu bidang yang perlu diperhatikan dan dikembangkan (Wawancara, Manulang, 2020).

Sejak Gereja masuk ke Indonesia ke daerah misi selalu memperhatikan pendidikan dan kesehatan untuk masyarakat setempat sehingga orang dicerdaskan pemikirannya terbuka yakni mempunyai pengetahuan yang luas dan juga kesehatannya harus diperhatikan dimanapun Gereja berada akan memperhatikan sekurang-kurang 2 aspek yakni pendidikan dan kesehatan maka Gereja ini mempunyai TK Santa Maria, SMP Santa Maria, dan SMA Santa Maria (Wawancara, Manulang, 2020)

TK Santa Maria posisinya di Guru H. Sulaiman kurang mengikuti pertumbuhan dan perkembangan yg di lakukan yayasan Gereja Katolik.

Sementara, perkembangan SD Santa Maria mengalami penurunan peningkatan karena sudah banyak sekolah-sekolah yang baru berdiri contohnya sekolah Dharma Yudha sehingga kesempatan untuk memasuki sebuah sekolah memasuki banyak dan berdampak pada pedoman pada peserta didik di sekolah.

SMP Santa Maria berkembag cukup baik, baik dari segi kuantitas atau sejumlah dari jumlah pendidikan karena sudah banyak dibangun sekolah-sekolah yang sudah di bangun.

Sedangkan pada SMA Santa Maria, memiliki perkembangan yang baik. Sebagimana yang lain, SMA Santa Maria sama juga dengan SD 
Santa Maria dan SMP Santa Maria yang mengalami penurunan dan pennignkatan disebabkan oleh banyaknya sekolah-sekolah yang baru ada.

Kedua, Fungsi di Bidang Sosial Masyarakat. Sebagai anggota masyarakat, semua orang harus diberi kesempatan untuk dapat hidup secara layak. Gereja juga memperhatikan hal ini, melalui karya-karyanya Gereja berusaha membantu agar masyarakat dapat hidup layak baik dari segi moril maupun spirituilnya. dalam kehidupan Gereja dan masyarakat. Keterlibatan itu dapat terjadi di berbagai bidang.

Gereja Katolik Pekanbaru berupaya menyumbangkan kemampuannya untuk memajukan masyarakat. Usaha ini dilakukan dengan berbagai cara baik melalui perseorangan maupun secara bersama-sama, terutama bagi umat Katolik yang tugas- duduk di lembaga pemerintah, secara khusus tentunya yang bersangkutan harus mau bekerja keras dan sungguhsungguh berupaya memajukan Gereja dan bangsa melalui tugas-tugas yang dilaksanakannya dengan baik dan sekaligus menampilka kesaksian imannya sebagai warga Gereja melalui tugas-tugas yang dijalankannya (Wawancara, Manulang, 2020).

Gereja Katolik Santa Maria mempunyai 3 ormas yakni;
Pertama, Perhimpunan Mahasiswa Katolik Republik Indonesia. Organisasi ini berhubungan dengan bagaimana mahasiswa berorganisasi dan berinteraksi dengan kelompokkelompok organisasi lainnya contohnya dengan organisasi HMI dan lainnya itu ada juga forum dan berdialog dengan ormas-ormas lainnya terutama dengan kelompok cipayung.

Kedua, Pemuda Katolik. Organisasi pemuda Katolik usianya sampai 35 tahun atau belum menikah bagi pemuda Katolikdan kalau PMKRI masih seusia mahasiswa kurang lebih di bawah 25 tahun

Ketiga, Wanita Katolik Republik Indonesia. Melalui ormas-ormas inilah kita bersosialisasi dan juga berinterksi dengan di luar Gereja itu misinya misi keluar berhubungan dengan semua ormas yang lain dan agama yang lain dan sebagainyaitu terjadinya dengan ormas-ormas lainnya contohnya dengan $\mathrm{NU}$ dan mengikuti upacara di makam Pahlawan dengan pemuka-pemuka agama lainnya itu bentuk komunikasi dengan sosial kemasyarakatan dan lewat ormas-ormas yang ada di Gereja Katolik.

Ketiga, Fungsi di Bidang Lembaga Kemasyarakatan. Gereja dan Negara merupakan dua lembaga yang saling berkaitan satu sama lainnya, yang punya kepentingan yang 
sama sekaligus tujuan yang berbeda dan tidak jarang seorang manusia sekaligus menjadi anggota dari kedua lembaga tersebut. Ini dapat terjadi karena Negara membutuhkan orangorang yang beriman dan berbudi pekerti dalam pembangunan bangsa dan Negara (Wawancara, Manulang, 2020).

Keempat, Fungsi di Bidang Politik. Gereja Katolik di bidang politik di sebut dengan Kerasulan awam walaupun Kerasulan awam tersebut memberikan dedukasi, memberikan informasi, pendampingan kepada umat awam itu terlibat dalam kehidupan berpolitik di anggota DPRD, sedangkan para rohani itu tidak boleh berpolitik praktis, yang diperbolehkan adalah dengan siraman rohani, memberikan nilai-nilai Katolikan dalam dalam berpolitik itu, berpolitik boleh tetapi harus memasukkan nilai-nilai Kekatolikan tentang menyuarakan keadilan, menyuarakan tentang cinta kasih, menyuarakan tentang advokasi atau hukum yang bertindas yang memberikan kerohanian kepada umat yang awam dalam kegiatan politikpolitik praktisi, partai-partai dan lembaga politik-politik yang ada (Wawancara, Manulang, 2020).

Kelima, Fungsi di Bidang Lingkungan Hidup. Gereja sendiri di beberapa daerah misalnya di Yogyakarta atau di Sumatera Utara atau di Semarang mempunyai suatu organisasi yang memang memperhatikan tentang lingkungan hidup, tentang keutuhan penciptaan berarti tentang manusia dan tentang alam itu di perhatikan tenang migran memang ada kelompok atau khusus di lingkungan hidup atau di singkat dari JFIS ( Justis Fis and Integrity gration) keadilan, damai, dan ketuhanan berarti meliputi lingkungan hidup, alam, dan manusia. Pada di bulan Mei kemaren Gereja Katolik secara universal itu berrefleksi tentang alam ciptaan Tuhan ini itu di pimpin oleh Paus dari Roma Vatikan yakni Paus Fransiskus dia yang mengajak Gereja itu untuk melihat kerusakan alam ini penyebabnya adalah perilaku manusia dan bagaimana membangun alam ini yakni dengan kesadaran manusia untuk memperhatikan lingkungan hidup.

Keenam, Fungsi di Bidang Liturgi. Bidang liturgy adalah yang terkait dengan peribadatan, terkait dengan do'a , penyembah alam untuk mengutamakan juga kerohanian utuk memelihara iman umat hal yang membedakan Gereja Katolik dan Gereja Protestan karena keduanya sama-sama menyembah tuhan Yesus jadi pengetahuan umat iman harus di bekali dengan mengetahui informasiinformasi tentang ibadat juga berbeda dengan mereka untuk memperkaya, 
mempertebal semakin memantapkan kerohanian atau iman dari umat iman sendiri lewat do'a-do'a, kerohanian, iutlah bagian-bagian liturgy untuk menambah kekuatan iman umat sendiri makanya liturgi Kristen Katolik dan Kristen Protestan liturginya itu tidak sama (Wawancara, Manulang, 2020).

Ketujuh, Fungsi di Bidang Pewartaan. Bidang pewartaan itu harus di kenal dulu 5tugas Gereja atau panca tugas Gereja

a. Pewartaan atau katakese

b. Kesaksian atau material

c. Liturgi

d. Colonial atau persekutuan

e. Pihaconia atau pelayanan jadi melayani untuk bidang pendidikan, kesehatan dan sebagainya.

Kedelapan, Fungsi di Bidang Kesehatan. Gereja Katolik mempunyai sebuah Rumah Sakit Santa Maria, seperti yang dikatakan tadi bahwasannya Gereja Katolik mempunyai perhatian terhadap pendidikan dan kesehatan, maka 2 hal itu dipertahankan oleh Gereja dimanapun Gereja itu berada pasti pendidikan dan kesehatan itu bawa untuk di sebar luaskan. Kegiatan di Rumah sakit pada hari Sabtu melakukan senam diabetes, senam untuk penyakit jantung di aula Rumah Sakit Santa Maria itu terkait dengan kesehatan.Menurut catatan dinas kesehatan Kota Pekanbaru
Rumah Sakit Santa Maria itu termasuk Rumah sakit yang terbuka untuk masyarakat karena itu merupakan ciri khas pelayanan Gereja Katolik Santa Maria (Wawancara, Manulang, 2020).

3. Kegiatan-kegiatan Gereja Katolik Santa Maria A. Fatimah Pekanbaru Pertama, Kegiatan Mingguan. Kegiatan Ibadah ini dilakukan satu seminggu sekali dengan melakukan doa'a bersama dan melakukan ibadah bersama di hari minggu di lingkungan Gereja Katolik Santa Maria Pekanbaru;

Kedua, Kegiatan Bulanan. Kegiatan bulanan ada hal-hal yang khusus selama bulan-bulan tertentu, jadi ngka setiap bulan itu ada kegiatan khusus. Pada bulan Februari dan Maret biasanya mereka itu persiapan hari raya Paska ada pendalaman kitab suci di lingkungan warga-warga sekitarnya ada 4 kali pertemuan dan pada bulan Mei di sepanjang bulan itu mereka biasanya berdo'a Rosario bersama dan pada bulan September itu mereka ada kesempatan untuk merenungkan kitab suci sepanjang bulan itu, di bulan Oktober itu melakukan Rosario do'a dalam butiran-butiran itu, jadi ampir setiap bulan ada kegiatan khas terkait dengan Ibadat di Gereja Katolik Santa Maria Pekanbaru.

Ketiga, Kegiatan Tahunan. Hari Raya Natal; Kegiatan tahunan 
memperingati perayaan hari raya natal yag dilakukan setiap tahunnya pada tanggal 25 desember yang diadakan di lingkungan Gereja Santa Maria Pekanbaru.

Paska. Kegiatan Paska ini diperingati setiap tahunnya pada bulan Maret dan April yang mana peringatan tersebut memperingati wafatnya Isa Al-Masih yang dilakukan pada bulan Maret dan Kenaikan Isa Al-Masih yang diperingati pada bulan April di lingkungan Gereja Katolik Santa Maria Pekanbaru.

Kegiatan Isidentil, yaitu Pembaptisan Bayi. Latar belakang pembaptisan bayi itu berhubung dengan kewajiban orang tua karena pada waktu mau menikah ada yang di sebut dengan penyelidikan kanonik itu ditekankan bahwa orang tua harus bertanggung jawab salah satunya adalah terhadap pendidikan anak dan tentunya pendidikan anak ini dikaitkan dengan kekatolikan.

Oleh sebab itu orang tua pasti mempunyai suatu pandangan dalam kekatolikan. Dalam Katolik suatu sangat berharga dan mencintai anaknya maka anaknya sedini mungkin itu harus di baptiskan tanggung jawab dari orang tua waktu menjelang pernikahan anaknya.

Dia berjanji untuk pendidikan anak ermasuk juga iman anak tersebut maka dengan berkaitan harus melakukan pembaptisan bayi. Tetapi orang tua harus kursus terlebih dahulu bagaimana berkaitan dengan ajaran Gereja, bagaimana dengan pendampingan anak, bagaimana pengetahuan-pengetahuan keagamaan Katolik (Wawancara, Susanto, 2020).

Pembaptisan

Dewasa. Pembaptisan dewasa itu tidak serta merta bahwa orang punya niat kemudian datang ke Gereja untuk mengungkapkan kepada penguru lalu di baptis itu tidak langsung di baptis karena ada kurikulum yang harus diikuti lalu ada tema-tema yang harus diajarkan kalau dia ikut secara rutin dan tidak pernah bolong biasanya satu minggu sekali pelajaran itu membutuhkan waktu selama 6 bulan adapun kurikulum yang harus di pelajari materi tentang Katolik, do'ado'a, tentang ke Allah Yesus Kristus, tentang ekaristi, sakramen, tentang Gereja kalau umat Katolik menekankan bahwa Gereja itu tidak berbatas dengan gedungnya, umat Katolik yang berkumpul percaya Yesus Kristus itu yang dinamakan Gereja (Wawancara, Susanto, 2020).

Pemberkatan Pernikahan. Dalam Katolik pernikahan itu memang dianjurkan ke Gereja dan Ibadatan dilakukan di Gereja atau tidak di Gereja bisa juga di Kapel (Gereja kecil) karena pernikahan itu tidk melibatkan 2 pribadi tetai juga melibatkan orang-orang lain sekaliguss bertindak sebagai saksi dalam 
pernikahan tersebut lalu saksi pernikahan itu yang di maksud kan adalah menghadiri pernikahan itu sekaligus sebagai saksi juga bagi yang sudah berkeluarga tentunya mengenang saat menikah dulu lalu sahnya pernikahan Katolik itu disahkan dengan saksi dari pihak perempuan dan laki-laki dan saksi ini tidak boleh yang berkaitan dengan keluarga harus orang lain yang menjadi dalam pernikahan itu yang diharapkan memberikan contoh ketika sudah berkeluarga. Untuk pengseahannya itu di sahkan oleh Imam atau pastor sebagai pengesahan dalam pernikahan (Wawancara, Susanto, 2020).
4. Realisasi Program Kerja Gereja Katolik Santa Maria

a. Kegiatan Ibadah Mingguan (Partahiyangan) ini dilakukan setiap seminggu sekali berjalan dengan baik.

b. Kegiatan peringatan hari raya Natal yang dilaksanakan setiap tahunnya pada tanggal 25 Desember namun kegiatan perayaan Natal berjalan dengan baik kegiatan paska yang dilaksanakan pada bulan Maret dan April yang kegiatan adalah kegiatan wafatnya Isa Al-Masih dan Kenaikan Yesus Kristus dan kegiatan ini berjalan dengan baik di Lingkungan Gereja

Tabel.1.

Struktur Kepengurusan Gereja di Santa Maria

\begin{tabular}{|l|l|l|}
\hline No & Nama & Jabatan \\
\hline 1 & Benedictus Manullang & Pastor Gereja Katolik Santa Maria \\
\hline 2 & Antonius Mulyono & Wakil ketua \\
\hline 3 & Harry Rau & Dewan penasehat \\
\hline 4 & Veronica Ermitha Dahliana Situngkir & Sekretaris \\
\hline 5 & Sofyan Efendi & Bendahara \\
\hline 6 & Karel K. Goran & Koordinator komisi 1 \\
\hline 7 & Ancilia Esmina Napitulu & Ketua seksi liturgy \\
\hline 8 & Simon Sapeai & Ketua seksi katakese \\
\hline 9 & Hendri Halim & Ketua kerasulan kitab suci dan ajaran Gereja \\
\hline 11 & drg. Sinta Buana & Koordinator komisi II \\
\hline 12 & dr. Junus Sutani & Ketua seksi kesehatan dan pendidikan \\
\hline 13 & Cindy Anggraini & Ketua seksi kepemudaan \\
\hline 14 & Ignatius Ewa & Ketua seksi bia dan bir \\
\hline 15 & Pasutri Hendri Taju & Ketua seksi pastoral keluarga \\
\hline 16 & Vinentius Sutono & Ketua seksi sosial \\
\hline 17 & Lusia Suryati & Ketua seksi pemberdayaan ekonomi umat \\
\hline 18 & Nicolas Situmorang & Ketua komsos, dokumentasi dan publikasi \\
\hline 19 & Harry Rau & Ketua seksi kerawam \\
\hline 20 & Rodbertus Leonardo Sukoso & Koordinator komisi IV \\
\hline 21 & Balutman Manik & Ketua seksi inventarius dan perlengkapan \\
\hline
\end{tabular}

Sumber: File Gereja Katolik Santa Maria, 2019 
Secara umum, tanggapan masyarakat lingkungan gereja Santa, cukup baik. Meskipun keberadaan Gereja Katolik Santa Maria adalah sangat tidak menganggu di sekitar masyarakat sekitar dan Gereja itu digunakan sebagai tempat Ibadah, selagi Gereja itu digunakan sebagai tempat Ibadah dan tempat mencari ilmu. Menurut bapak Budi selaku pedagang merasa tidak menganggu dengan keberadaan Gereja Katolik Santa Maria.

Hubungan Masyarakat disekitar Gereja tersebut sangat baik dan merasa tidak terasingkan dan sudah dianggap keluarga dan sering melakukan kegiatankegiatan bersama orang non muslim. Bapak Budi selaku pedagang di sekitar Gereja sangat tidak terganggu orang non Muslim membeli dagangan bapak Budi (Wawancara, Budi, 2019).

Menurut bapak Hendra tanggapan tentang keberadaan Gereja Katolik itu merasa tidak menganggu keberadaan Gereja itu baik-baik saja dan hubungan masyarakat muslim dengan orang non muslim itu hubungannya baik-baik saja dan tidak terasingkandnan mejadi warga yang baik dengan umat Islam

\section{Kesimpulan}

Secara eksistensial, Rumah Ibadah dalam sebuah agama, sejatinya memiliki kesamaan. Karena perintah pendiriannya, juga untuk menunaikan Ibadah yang utama.

Begitu pula secara fungsional, masjid dan gereja Katolik Santa Maria, memiliki persamaan di fungsi bidang pendidikan, yang mana fungsi pendidikan di Masjid didirikan TK dan MDTA, sedangkan fngsi pendidikan di Gereja Katolik Santa Maria didirikan TK Santa Maria, SD Santa Maria dan SMA Santa Maria. 


\section{DAFTAR PUSTAKA}

Dr. Huri Yasin Husain, 2011. Fikih Masjid. Jakarta. Pustaka Al-Kautsar,

Filla Lailatul Hudriyah, Dakwah Melalui Optimalisasi FungsiMasjidAl-Awwabin Perum Mijen Permai Kel. Mijen Kec. Mijen KotaSemarang, 2018, Skripsi sarjana semarang: UIN Walisongo Semarang,

Tarpin dan Khotimah, Agama Katolik dan Yahudi, 2011, Pekanbaru: Daulat Riau

File Gereja Katolik Santa Maria

Tarpin dan Khotimah, Agama Katolik dan Yabudi, 2011, Pekanbaru: Daulat Riau

Ahmad Mahpur Eksistensi Ruh Dalam Perspektif Ibnu Arabi, skripsi sarjana Lampung: UIN Raden Intan Lampung

Anang Fatkhur Rohman, Peran Gereja Santa Maria Tak Bernoda dalam Megaplikasikan Karya Pastoral terbadap KLMTD di Paroki Nanggulan, skripsi sarjana Yogyakart:UIN Sunan Kalijaga Yogyakart,

Dr. Huri Yasin Husain, 2011. Fikih Masjid. Jakarta. Pustaka Al-Kautsar,

Filla Lailatul Hudriyah, Dakwah Melalui Optimalisasi Fungsi Masjid AlAwwabin Perum Mijen Permai Kel. Mijen Kec. Mijen Kota Semarang, 2018, Skripsi sarjana semarang: UIN Walisongo Semarang,

M. Arif Bahru Shofa,Masjid Sebagai Kegiatan Sosial, Skripsi Sarjana: IAIN Ponorogo,
Muhammad Arif Bahru Shofa, Masjid Sebagai Pusat Kegiatan Sosial, skripsi sarjana Ponorogo: IAIN Ponorogo,

Nakia Hana Sakova, Penolakan Masyarakat Terhadap Pendirian Rumah Ibadah dalam Perspektif Hak Asasi Manusia, skripsi sarjana jakarta: UIN syarif Hidayatullah Jakarta,

Nur Shabrina, Penyelesaian Konflik Rumah Ibadah, skripsi sarjana: UIN Syarif Hidayatullah Jakarta,

Puspa Djuwita, Studi Komparatif, Bengkulu,

Rukiyanto, B.A, Peran Gereja Katolik dalamMembangun Bangsa Indonesi di Era Reformasi, Vol. 16, No. 2 Oktober 2017: Yogyakarta,

Sakia Hana Sakova, Penolakan Masyarakat Terbadap Pendirian Rumah Ibadah dalam Perspektif Hak Asasi Manusia, skripsi sarjana jakarta: UIN syarif Hidayatullah Jakarta,

Syamsul Kurniawan, "Masjid dalam Lintasan Sejarah UmatIslam", dalam Jurnal Khatulistiwa Vol. 4, No. 2 September 2014. Institut Agama Islam Pontianak,

Tarpin dan Khotimah, Agama Katolik dan Yahudi, 2011, Pekanbaru: Daulat Riau

Syamsul Kurniawan, "Masjid dalam Lintasan Sejarah Umat Islam", dalam Jurnal Khatulistiwa Vol. 4, No. 2 September 2014. Institut Agama Islam Pontianak,

File adm Gereja Katolik Santa Maria

Filla Lailatul Hudriyah, Dakwah Melalui Optimalisasi Fungsi Masjid Al- 
Awwabin Perum Mijen Permai Kel. Mijen Kec. Mijen Kota Semarang, 2018, Skripsi sarjana semarang: UIN Walisongo Semarang,

Syamsul Kurniawan, "Masjid dalam Lintasan Sejarah Umat Islam", dalam Jurnal Khatulistiwa Vol. 4, No. 2 September 2014. Institut Agama Islam Pontianak, 